\title{
A Mechano- and Thermoresponsive Photoluminescent Supramolecular Polymer
}

\author{
Anna Lavrenova, ${ }^{\dagger}$ Diederik W. R. Balkenende, ${ }^{\dagger, t}$ Yoshimitsu Sagara, ${ }^{\S}$ Stephen Schrettl, ${ }^{\dagger}$ Yoan C. \\ Simon $^{\dagger, l}$ and Christoph Weder* ${ }^{\dagger}$ \\ ${ }^{\dagger}$ Adolphe Merkle Institute, University of Fribourg, Chemin des Verdiers 4, 1700 Fribourg, Switzerland \\ ${ }^{\ddagger}$ Department of Bioengineering and Materials Science and Engineering, University of California Berkeley, Hearst Mining \\ Building, Berkeley, California 94720-1760, USA \\ ${ }^{\S}$ Research Institute for Electronic Science, Hokkaido University, N20, W10, Kita-Ku, Sapporo 001-0020, Japan \\ 'School of Polymers and High Performance Materials, The University of Southern Mississippi, 118 College Dr., Box 5050, \\ Hattiesburg, Mississippi, 39406, USA
}

Supporting Information Placeholder

\begin{abstract}
Mechanoresponsive luminescent (MRL) materials change their emission color upon application of external forces. Many dyes with MRL behavior are known, but they normally do not display useful mechanical properties. Here, we introduce a new approach to overcome this problem, which relies on combining MRL compounds with the concept of supramolecular polymerization. As a first embodiment, a cyano-substituted oligo( $p$-phenylene vinylene), whose MRL behavior is associated with different solid-state assemblies, was derivatized with two ureido-4-pyrimidinone groups, which support the formation of a dynamic supramolecular polymer. The new material displays the thermomechanical characteristics of a supramolecular polymer glass, offers three different emission colors in the solid state, and exhibits both MRL and thermoresponsive luminescent behavior.
\end{abstract}

Reversible non-covalent interactions can bestow materials with stimuli-responsive characteristics and introduce functions such as the ability to heal, adaptive adhesion, or mechanochromism. ${ }^{1}$ Non-covalent interactions also play a role in MRL materials, whose emission color changes upon application of mechanical forces. ${ }^{1 \mathrm{a}, 1 \mathrm{~b}, 2}$ Fueled by academic curiosity and the potential use in applications that range from data storage to advanced sensing schemes, ${ }^{2}$ hundreds of MRL dyes have been reported. ${ }^{1 b, 3}$ Their emission is typically influenced by molecular packing, notably the conformation of molecules and interactions between them, which can be altered mechanically. ${ }^{1 b, 2 b, 3 b}$ Most MRL compounds allow switching between two emissive states, whereas multi-color dyes are more rare. ${ }^{4}$ Hundreds of papers reported powder-like MRL substances whose fluorescence can be changed by grinding, but it proved challenging to harness this effect in materials that can be used to create possibly useful objects, e.g., items indicating wear, tear, or imminent failure through a fluorescence color change. ${ }^{\mathrm{lb}, \mathrm{lg}}$ This problem can a priori be solved by incorporating MRL dyes into mechanically robust polymers, ${ }^{3 a, 5}$ but examples based on this approach are limited, arguably because connecting MRL behavior with polymer deformation is not necessarily a trivial matter. Another strategy is the introduction of mechanophores into polymers, but examples of corresponding materials with mechanically changeable fluorescence are also limited. ${ }^{6}$

We here introduce an alternative approach that relies on the derivatization of MRL chromophores with supramolecular binding motifs. The latter promote self-assembly into a supra- molecular polymer and transform dyes into materials that merge MRL behavior with the mechanics of macromolecular materials. As a first embodiment of this design, the cyano-substituted oligo( $p$-phenylene vinylene) (cyano-OPV) 1,4-bis $(\alpha$-cyano-4(12-hydroxydodecyloxy)styryl)-2,5-dimethoxybenzene (1),,$^{\text {a, } 7}$ whose MRL behavior is related to ground state aggregates and excimers, ${ }^{3 \mathrm{a}, 4 \mathrm{a}, 8}$ was end-functionalized with self-complementary hydrogen-bonding ureido-4-pyrimidinone (UPy) groups. ${ }^{1 \mathrm{c}, 9}$ This was achieved by reacting 1 with 2-(6-isocyanatohexylaminocarbonylamino)-6-methyl-4[1H]pyrimidinone, ${ }^{9-10}$ using dibutyltin dilaurate (DBTL) as catalyst and conducting the reaction in hot pyridine, affording the supramolecular monomer $\mathbf{2}$ in good yield (69\%, Figure 1a). The design was rationalized by a recent study on supramolecular polymer glasses, ${ }^{11}$ and exploits orthogonal non-covalent interactions; ${ }^{9,12}$ hydrogen-bonds are utilized to support supramolecular polymerization, whereas $\pi-\pi$ stacking directs the packing of the chromophores (Supporting Discussion).

The thermogravimetric analysis trace shows that $\mathbf{2}$ is stable up to ca. $240{ }^{\circ} \mathrm{C}$ ( $2 \%$ weight loss, Figure S3a). The differential scanning calorimetry (DSC) trace of an as-prepared sample (obtained by precipitation from pyridine into acetone) shows a glass transition temperature $\left(T_{\mathrm{g}}\right)$ at ca. $80{ }^{\circ} \mathrm{C}$ and two endothermic transitions around 145 and $168{ }^{\circ} \mathrm{C}$ (Figure 2a). Upon cooling from the melt, an exothermic transition is detected around $132^{\circ} \mathrm{C}$ and a $T_{\mathrm{g}}$ is seen at ca. $100{ }^{\circ} \mathrm{C}$. The second heating scan is clearly different from the first, showing a $T_{\mathrm{g}}$ at ca. $90{ }^{\circ} \mathrm{C}$ and endothermic transitions around 136,148 and $172{ }^{\circ} \mathrm{C}$. The second and the third heating scans are identical, the second cooling trace matches the first (Figure S3b), a comparison of the ${ }^{1} \mathrm{H}$ and ${ }^{13} \mathrm{C}$ NMR spectra of pristine and heat-treated samples reveals no chemical changes (Figures S7, S8), and the melted material can be converted back to the original form by re-precipitation (Figure S6). These data reflect that $\mathbf{2}$ can be kinetically trapped in a metastable state by precipitation and transformed into a thermodynamically more favorable form upon heating above the melting transition and subsequent cooling. The comparison of the DSC data of $\mathbf{2}$ with the DSC traces of the liquid crystalline (LC) UPy-free $\mathbf{1}$ and mixtures of 1 and $\mathbf{2}$ (Figure S24, S25) suggests that upon precipitation, $\mathbf{2}$ forms a largely disordered molecular solid, which is converted into a supramolecular polymer upon heating and cooling. The endotherms seen in the DSC of the latter suggest 
melting of a small crystalline portion, the formation of an LC phase, and the transition to the isotropic melt, respectively.

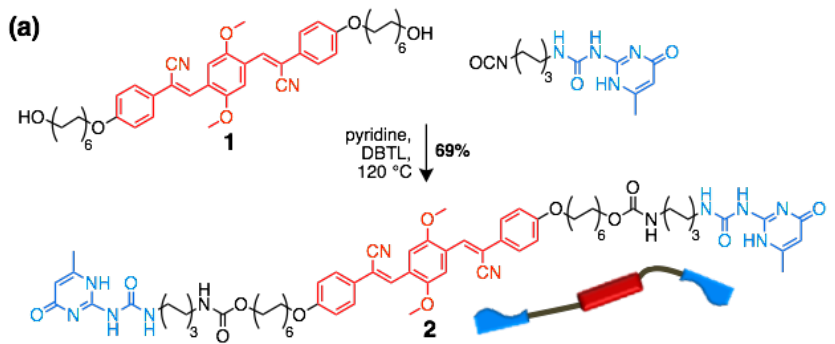

(b)

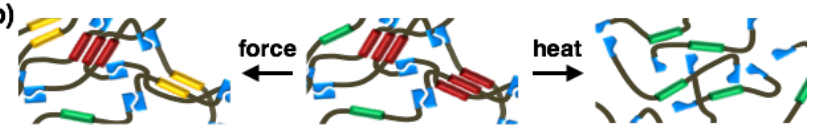

(c)
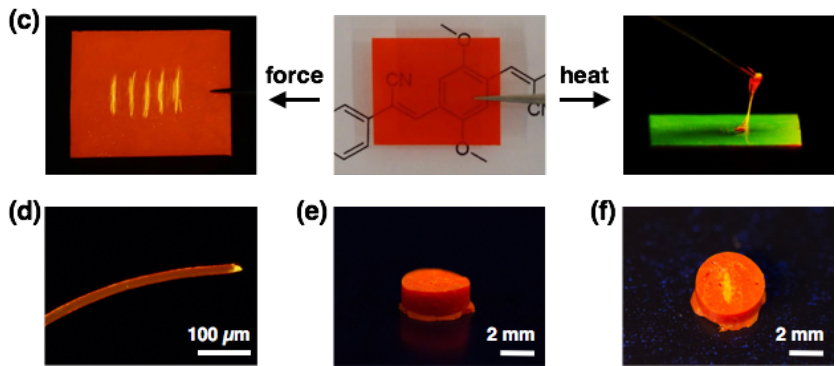

Figure 1. (a) Synthesis of the UPy-functionalized cyano-OPV 2. (b) Schematic of supramolecular assemblies. (c) Pictures of films made from 2, illustrating mechano- (left) and thermoresponsive (right) luminescent behavior. The fluorescence changes from red to yellow upon scratching (left). Upon heating $\left(180^{\circ} \mathrm{C}\right)$ a viscous green-light-emitting fluid is formed, which solidifies into a red-light emitting solid when cooled (right). (d) Fluorescence microscopy image of a fiber made from 2; note the yellow fluorescing severed edge. (e,f) Photographs of a cylinder made from 2 before (e) and after (f) scratching its surface. Images displaying fluorescence were recorded under illumination with $365 \mathrm{~nm}$ UV light.

The pictures shown in Figure 1c-f, and Figures S15a, S17, S19-S23 demonstrate that 2 can readily be melt-processed into objects of various shapes which exhibit polymer-like properties. Self-supported films were made by compression molding, cylinders that could carry a load exceeding their weight by 5 orders of magnitude were fabricated with a simple mold, and fibers could easily be drawn from the melt. As the latter process requires a viscosity that can only be attained with macromolecular materials, the fiber-forming capability qualitatively reflects that even at elevated temperature a portion of the UPy groups is dimerized and that 2 assembles into a supramolecular polymer. For reference purposes, we also attempted to produce similar objects from the UPy-free cyano-OPV 1 (Figures S14, S15b, S16, S18), but on account of the compound's low molecular weight, no fibers could be drawn and films and cylinders were inhomogeneous and brittle (Figures S14, S16, S18). This prevented mechanical testing of films made from 1, whereas dynamic mechanical analysis (DMA) was readily possible for compression-molded films of $\mathbf{2}$. The DMA trace reveals a room-temperature storage modulus of $1.45 \pm 0.06 \mathrm{GPa}$, a high-modulus regime that extends to ca. $60{ }^{\circ} \mathrm{C}$, and a modulus drop above this temperature on account of the glass transition, which the loss tangent $(\tan \delta)$ curve puts at ca. $95{ }^{\circ} \mathrm{C}$ (Figure $2 \mathrm{~b}$ ). A three-point bending test confirmed the high stiffness at $25^{\circ} \mathrm{C}$ (flexural modulus of $1.50 \pm 0.06 \mathrm{GPa}$ ) and afforded flexural stress and strain at break values of $6.0 \pm 0.2 \mathrm{MPa}$ and $0.4 \pm 0.01 \%$, respectively (Figure 2c). Thus, 2 assembles into a substantially glassy, rigid, and somewhat brittle supramolecular polymer. Its mechanical properties are similar to those of a recently reported supramolecular network polymer based on a trifunctional low-molecular weight monomer carrying three UPy groups. ${ }^{11}$ (a)

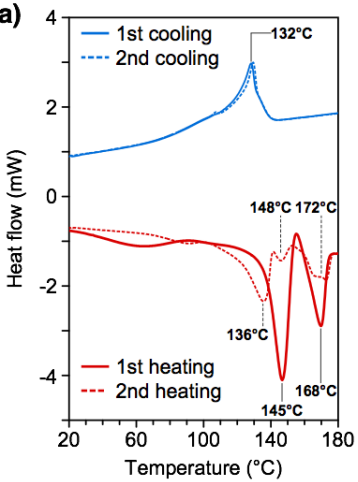

(c)

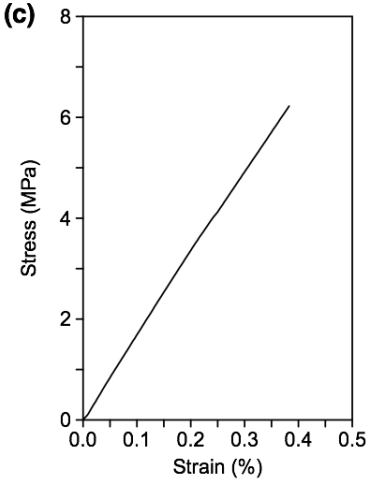

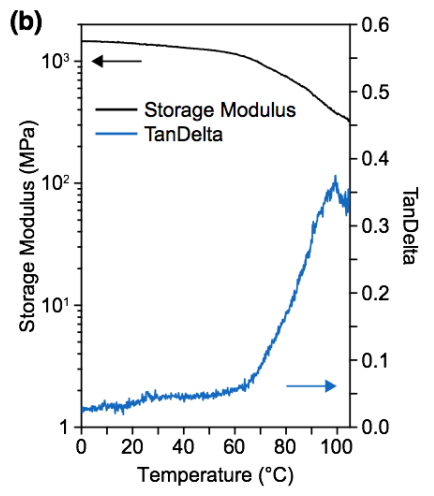

(d)

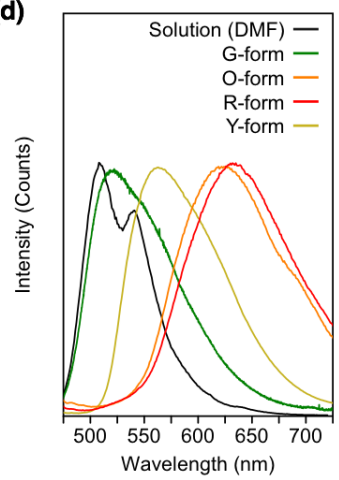

(e)

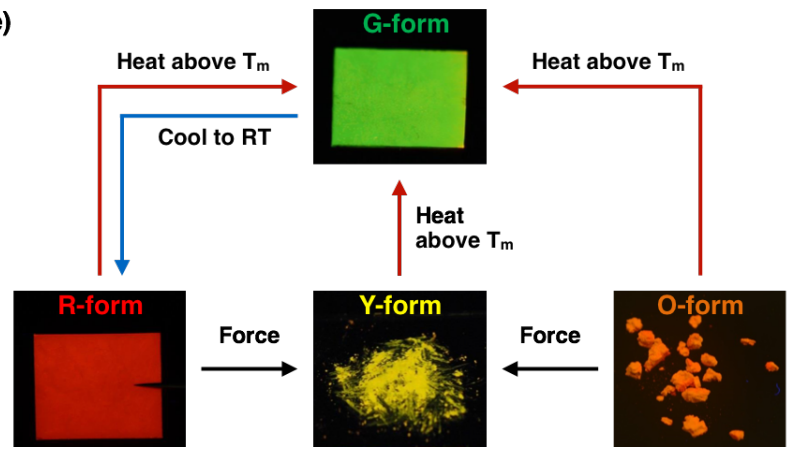

Figure 2. (a) DSC scans of the first and second heating and cooling of as prepared $2\left(10{ }^{\circ} \mathrm{C} / \mathrm{min}\right)$. (b) DMA traces (storage modulus and $\left.\tan \delta\right)$ and (c) stress-strain curve (at $25^{\circ} \mathrm{C}$ ) of a compression-molded film of 2 . (d) Normalized photoluminescence spectra of 2 in DMF $\left(1 \cdot 10^{-4} \mathrm{M}, 80^{\circ} \mathrm{C}\right)$, the $\mathrm{G}$-form at $180^{\circ} \mathrm{C}$, and the $\mathrm{Y}-, \mathrm{O}-$, and $\mathrm{R}$ - forms at room temperature $\left(\lambda_{\mathrm{ex}}=380 \mathrm{~nm}\right.$ for solution, Y-, O-, R- forms, $370 \mathrm{~nm}$ for G-form). (e) Pictures of $\mathbf{2}$ in different forms. Arrows indicate conversions by the indicated stimuli. Images were taken under illumination with $365 \mathrm{~nm}$ UV-light at room temperature (R-, Y-, and O-forms) or $180^{\circ} \mathrm{C}$ (G-form).

Compound 2 and its supramolecular assemblies can display four different emission colors - orange, red, yellow, and green depending on the thermomechanical history and the environmental conditions (Figures 1c, 2d,e). As prepared (i.e., in the metastable form obtained by precipitation), $\mathbf{2}$ emits orange light (Figure 2e). The emission spectrum of this $\mathrm{O}$-form displays a broad featureless peak with a maximum $\left(\lambda_{\max }\right)$ at $622 \mathrm{~nm}$ (Figure 2d), indicative of ground-state chromophore aggregates and excimer emission. ${ }^{3 \mathrm{a}, 8 \mathrm{~b}, 13}$ Heating the material to ca. $180^{\circ} \mathrm{C}$, i.e., above $T_{\mathrm{m}}$, changes the fluorescence color to green (G-form) with a $\lambda_{\max }$ of ca. $520 \mathrm{~nm}$; the same emission color is observed for a dilute solution of 2 in hot DMF $\left(1 \cdot 10^{-4} \mathrm{M}\right.$, ca. $\left.80^{\circ} \mathrm{C}\right)$ for which the emission spectrum shows peaks at 508 and $540 \mathrm{~nm}$ and a lifetime of $1.4 \mathrm{~ns}$ was measured (Figure $2 \mathrm{~d}$ and Figure S4). These parameters suggest that in solution and the melted state, the emissive cyano-OPV cores are dissociated from another and emission occurs from the monomer (as opposed to excimer) state. ${ }^{3 a, 8 b}$ Cooling the G-form to room temperature affords a red-light-emitting solid (R-form, generally prepared by annealing 
at $180{ }^{\circ} \mathrm{C}$ for $5 \mathrm{~min}$ ), whose broad structure-less emission band displays a maximum around $633 \mathrm{~nm}$ (Figure 2d). The emission lifetimes of the O- and R-form were 25.8 and 24.9 ns, respectively, indicative of the formation of excimers in both cases (Figure S4). While the spectroscopic differences of forms accessed by either precipitation (O-form) or cooling from the melt (R-form) are small, DSC experiments (vide supra) suggest that the two structures are indeed different. This is further supported by powder X-ray diffraction patterns (Figure 3a), which indicate that both forms are largely amorphous and only feature a small fraction of ordered domains. However, the latter are clearly different (as indicated by the diffraction peaks), and may influence or even dominate the emission properties, since cyano-OPV assemblies typically display a smaller optical gap than the monomeric species, ${ }^{3 a, 13}$ and energy transfer processes can channel the emission to these low-energy states.

The MRL behavior of $\mathbf{2}$ manifests itself upon grinding the $\mathrm{O}$ and R-forms. In both cases, the same yellow light emitting form (Y-form) was obtained (Figure 2e). The Y-form exhibits a broad emission spectrum with a maximum around $562 \mathrm{~nm}$, which is significantly blue-shifted vis-à-vis the $\mathrm{O}$ - and $\mathrm{R}$-forms (Figure 2d). The fluorescence lifetime of the Y-form is $14.6 \mathrm{~ns}$ and therewith much shorter than that of the $\mathrm{O}$ - and $\mathrm{R}$-forms, but much longer than that of the 2 solution in hot DMF (1.4 ns, Figure S4). Thus, the photophysical characteristics suggest that the emission of the Y-form is also likely related to the formation of excimers, although the emissive species are clearly different from those in the $\mathrm{O}$ - and $\mathrm{R}$-forms. This interpretation is supported by powder XRD data, which show that the Y-form is largely amorphous (Figure 3a). Heating the Y-form for $1 \mathrm{~min}$ at $180{ }^{\circ} \mathrm{C}$ (above $T_{\mathrm{m}}$ ) and subsequent cooling to room temperature restored the R-form, as evidenced by the appearance (Figure 2e), the red-shift of the emission maximum from $562 \mathrm{~nm}$ to $630 \mathrm{~nm}$ (Figure S10), the emission lifetime (30.7 ns, Figure S4), and the powder XRD pattern (Figure S11). The thermally induced transformation of the Y-form into the R-form was also confirmed by DSC; an exothermic peak around $80{ }^{\circ} \mathrm{C}$ is seen upon the first heating of the Y-form, which is interpreted as crystallization, followed by two endothermic transitions around 135 and $168{ }^{\circ} \mathrm{C}$ (Figure S12a), which are also observed for the R-form (Figure S12b). This corroborates that the $\mathrm{O}$ - and $\mathrm{Y}$-form are both kinetically trapped by either precipitation (O-form) or mechanical treatment (Y-form), and are converted to the thermodynamically stable R-form when cooled from the melt.
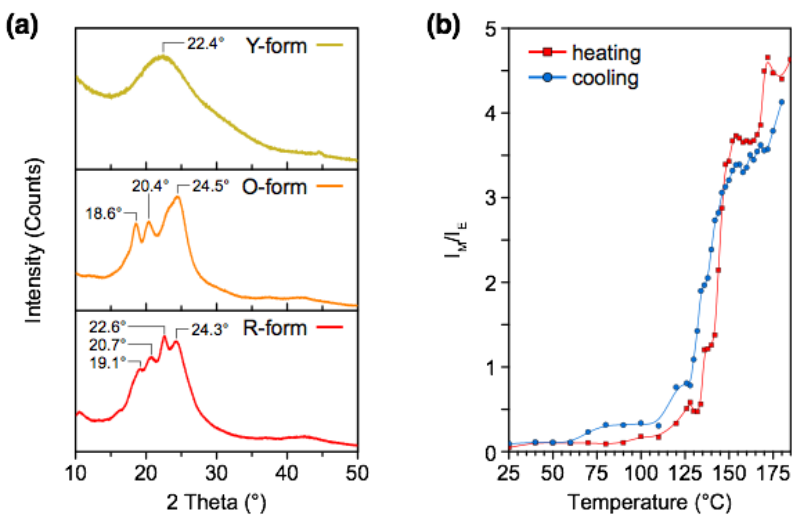

Figure 3. (a) Powder XRD patterns of $\mathbf{2}$ in the Y-, O-, and R-form. (b) Ratio of monomer $\left(\mathrm{I}_{\mathrm{M}}\right)$ and excimer $\left(\mathrm{I}_{\mathrm{E}}\right)$ emission intensities recorded at 522 and $625 \mathrm{~nm}$ of the R-form of 2 as function of temperature. B-spline functions connect the data points acquired upon heating and cooling.

To investigate the disassembly of the cyano-OPVs upon heating and correlate the optical changes with thermal transitions, the fluorescence spectrum of $\mathbf{2}$ was recorded as a function of temperature, starting from the R-form (Figure S13), and the thermochromic response was monitored by the ratio of monomer to excimer emission intensities $\left(\mathrm{I}_{\mathrm{M}} / \mathrm{I}_{\mathrm{E}}\right)$ recorded at $522 \mathrm{~nm}$ and $625 \mathrm{~nm}$ (Figure $3 \mathrm{~b}$ ). Upon heating, $\mathrm{I}_{\mathrm{M}} / \mathrm{I}_{\mathrm{E}}$ changes in three "steps", which appear to coincide with the endothermic transitions (132, $148,172{ }^{\circ} \mathrm{C}$ ) observed in the DSC experiments (Figure 2a), although the change is most pronounced around the transition centered at $148{ }^{\circ} \mathrm{C}$. Heating above $T_{\mathrm{m}}\left(172{ }^{\circ} \mathrm{C}\right)$ leads to complete dissociation of the cyano-OPV aggregates, as indicated by the appearance of green monomer $(522 \mathrm{~nm})$ and disappearance of red excimer $(625 \mathrm{~nm})$ emission (Figure S13). The data acquired during cooling paint the same picture; a sharp decrease of $\mathrm{I}_{\mathrm{M}} / \mathrm{I}_{\mathrm{E}}$ is seen when the temperature is lowered to ca. $140{ }^{\circ} \mathrm{C}$. At the same point, a pronounced exothermic transition is observed in the DSC cooling scan, which indicates partial crystallization and conversion of the G- into the R-form.

In stark difference to the UPy-free cyano-OPV 1, which does not display any useful mechanical properties, $\mathbf{2}$ allows exploiting the MRL effect in actual objects and under possibly useful scenarios. For example, scratching a compression-molded film causes yellow-light emitting marks (Figure 1c) with blue-shifted emission (Figure S5). The same color change occurs upon cutting the cylinders and fibers (Figures 1d, S20, S23).

In summary, we have introduced a new approach for the design of supramolecular materials with MRL behavior. In contrast to previously reported low-molecular-weight thermo- and mechanochromic compounds, the supramolecular polymer formed by the self-assembly of $\mathbf{2}$ can be molded into self-supporting objects of various shapes. The new material displays the thermomechanical characteristics of a supramolecular polymer glass, offers three different emission colors in the solid state, and exhibits both MRL and thermoresponsive behavior. The concept appears applicable to other MRL molecules and supramolecular binding motifs and should be broadly exploitable to create useful materials with rich stimuli-responsive behavior.

\section{ASSOCIATED CONTENT}

\section{Supporting Information}

This material is available free of charge via the Internet at http://pubs.acs.org.

\section{AUTHOR INFORMATION \\ Corresponding Author}

*christoph.weder@unifr.ch

\section{Notes}

The authors declare no competing financial interest.

\section{ACKNOWLEDGMENT}

The research leading to these results has received funding from the European Research Council under the European Union's Seventh Framework Programme (FP7/2007 - 2013) / ERC grant agreement $\mathrm{n}^{\circ}$ AdG 291490-MERESPO. Additional funding from the NCCR Bio-Inspired Materials and the U.S. Army Research Office (W911NF-12-1-0339) is acknowledged. The authors thank Profs. B. Grobéty and Y. Urano for assistance with XRD and emission lifetime measurements, respectively.

\section{REFERENCES}

(1) (a) Haehnel, A. P.; Sagara, Y.; Simon, Y. C.; Weder, C., Top. Curr. Chem. 2015, 369, 345-375. (b) Sagara, Y.; Yamane, S.; Mitani, M.; Weder, C.; Kato, T., Adv. Mater. 2016, 25, 1073-1095. (c) Brunsveld, L.; Former, B. J. B.; Meijer, E. W.; Sijbesma, R. P., Chem. Rev. 2001, 101, 4071-4097. (d) Balkenende, D. W. R.; Coulibaly, S.; Balog, S.; Simon, Y. C.; Fiore, G. L.; Weder, C., J. Am. Chem. Soc. 2014, 136, 10493-10501. (e) Yan, X.; Wang, F.; Zhenga, B.; Huang, F., Chem. Soc. Rev. 2012, 41, 6042-6065. (f) Aida, T.; 
Meijer, E. W.; Stupp, S. I., Science 2012, 335, 813-817. (g) Calvino, C; Neumann, L.; Weder, C; Schrettl, S., J. Polym. Sci. Part A: Polym. Chem. 2017, 55, 640-652.

(2) (a) Pucci, A.; Ruggeri, G., J. Mater. Chem. 2011, 21 , 8282-8291. (b) Pucci, A.; Bizzarri, R.; Ruggeri, G., Soft Matter 2011, 7, 3689-3700.

(3) (a) Löwe, C.; Weder, C., Adv. Mater. 2002, 14, 1625-1629. (b) Sagara, Y.; Kato, T., Nat. Chem. 2009, 1, 605-610. (c) Ito, H.; Saito, T.; Oshima, N.; Kitamura, N.; Ishizaka, S.; Hinatsu, Y.; Wakeshima, M.; Kato, M.; Tsuge, K.; Sawamura, M., J. Am. Chem. Soc. 2008, 130, 10044-10045. (d) Wang, J.; Mei, J.; Hu, R.; Sun, J. Z.; Qin, A.; Tang, B. Z., J. Am. Chem. Soc. 2012, 134, 9956-9966. (e) Chung, J. W.; You, Y.; Huh, H. S.; An, B.-K.; Yoon, S.-J.; Kim, S. H.; Lee, S. W.; Park, S. Y., J. Am. Chem. Soc. 2009, 131, 8163-8172. (f) Sagara, Y.; Mutai, T.; Yoshikawa, I.; Araki, K., J. Am. Chem. Soc. 2007, 129, 1520-1521. (g) Zhang, G.; Lu, J.; Sabat, M.; Fraser, C. L., J. Am. Chem. Soc. 2010, 132, 2160-2162. (h) Teng, M.-J.; Jia, X.-R.; Yang, S.; Chen, X.-F.; Wei, Y., Adv. Mater. 2012, 24, 1255-1261.

(4) (a) Sagara, Y.; Lavrenova, A.; Crochet, A.; Simon, Y. C.; Fromm, K. M.; Weder, C., Chem. Eur. J. 2016, 22, 4374-4378. (b) Sagara, Y.; Kato, T., Angew. Chem. Int. Ed. 2011, 50, 9128-9132. (c) Seki, T.; Ozaki, T.; Okura, T.; Asakura, K.; Sakon, A.; Uekusa, H.; Ito, H., Chem. Sci. 2015, 6, 2187-2195. (d) Ma, Z.; Wang, Z.; Teng, M.; Xu, Z.; Jia, X., ChemPhysChem 2015, 16, 1811-1828. (e) Yagai, S.; Okamura, S.; Nakano, Y.; Yamauchi, M.; Kishikawa, K.; Karatsu, T.; Kitamura, A.; Ueno, A.; Kuzuhara, D.; Yamada, H.; Seki, T.; Ito, H., Nat. Commun. 2014, 5, 413-417. (f) Kim, H.-J.; Whang, D. R.; Gierschner, J.; Lee, C. H.; Park, S. Y., Angew. Chem. Int. Ed. 2015, 54, 4330-4333. (g) Ma, Z.; Wang, Z.; Meng, X.; Xu, Z.; Ma, Y.; Jia, X., Angew. Chem. Int. Ed. 2016, 55, 519-522.

(5) (a) Crenshaw, B. R.; Weder, C., Macromolecules 2006, 39, 9581-9589. (b) Ciardelli, F.; Ruggeri, G.; Pucci, A., Chem. Soc. Rev.
2013, 42, 857-870. (c) Donati, F.; Pucci, A.; Cappelli, C.; Mennucci, B.; Ruggeri, G., J. Phys. Chem. B 2008, 112, 3668-3679. (d) Kunzelman, J.; Crenshaw, B.; Kinami, M.; Weder, C., Macromol. Rapid Commun. 2006, 27, 1981-1987.

(6) (a) Davis, D. A.; Hamilton, A.; Yang, J.; Cremar, L. D.; Van Gough, D.; Potisek, S. L.; Ong, M. T.; Braun, P. V.; Martínez, T. J.; White, S. R.; Moore, J. S.; Sottos, N. R. Nature 2009, 459, 68-72. (b) Lee, C. K.; Davis, D. A.; White, S. R.; Moore, J. S.; Sottos, N. R.; Braun, P. V. J. Am. Chem. Soc. 2010, 132, 16107-16111. (c) Kingsbury, C. M.; May, P. A.; Davis, D. A.; White, S. R.; Moore, J. S.; Sottos, N. R. J. Mater. Chem. 2011, 21, 8381-8388. (d) Chen, Y.; Spiering, A. J. H.; Karthikeyan, S.; Peters, G. W. M.; Meijer, E. W.; Sijbesma, R. P. Nature Chem. 2012, 4, 559-562. (e) Grady, M. E.; Beiermann, B. A.; Moore, J. S.; Sottos, N. R. ACS Appl. Mater. Interfaces 2014, 6, 5350-5355.

(7) Kunzelman, J.; Crenshaw, B. R.; Weder, C., J. Mater. Chem. 2007, 17, 2989-2991.

(8) (a) Kunzelman, J.; Kinami, M.; Crenshaw, B. R.; Protasiewicz, J. D.; Weder, C., Adv. Mater. 2008, 20, 119-124; (b) Crenshaw, B. R.; Weder, C., Chem. Mater. 2003, 15, 4717-4724.

(9) Sijbesma, R. P.; Beijer, F. H.; Brunsveld, L.; Folmer, B. J. B.; Hirschberg, J. H. K.; Lange, R. F. M.; Lowe, J. K. L.; Meijer, E. W., Science 1997, 278, 1601-1604.

(10) (a) Folmer, B. J. B.; Sijbesma, R. P.; Versteegen, R. M.; Rijt, J. A. J. v. d.; Meijer, E. W., Adv. Mater. 2000, 12, 874-878. (b) Greef, T. F. A. D.; Smulders, M. M. J.; Wolffs, M.; Schenning, A. P. H. J.; Sijbesma, R. P.; Meijer, E. W., Chem. Rev. 2009, 109, 5687-5754.

(11) Balkenende, D. W. R.; Monnier, C. A.; Fiore, G. L.; Weder, C., Nat. Commun. 2016, 710995.

(12) Wojetecki, R. J.; Meador, M. A.; Rowan, S. J., Nat. Mater. 2011, 10, 14-27.

(13) Löwe, C.; Weder, C., Synthesis 2002, 9, 1185-1190. 
A Mechano- and Thermoresponsive Photoluminescent Supramolecular Polymer

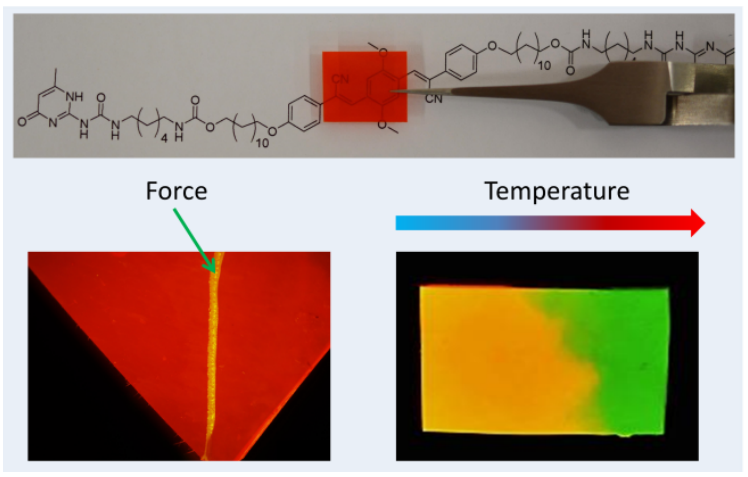

